\title{
Advance directives empower users and need professionals for implementation Michaela Amering ${ }^{* 1,2}$ and Markus Schaffer ${ }^{1}$
}

Address: ${ }^{1}$ Department of Psychiatry, Medical University of Vienna, Waehringer Guertel 18-20, 1090 Vienna, Austria and ${ }^{2}$ Ludwig Boltzmann Institute for Social Psychiatry, Spitalgasse 11, 1090 Vienna, Austria

* Corresponding author

from WPA Thematic Conference. Coercive Treatment in Psychiatry: A Comprehensive Review

Dresden, Germany. 6-8 June 2007

Published: 19 December 2007

BMC Psychiatry 2007, 7(SuppI I):SII0 doi:10.1I86/147I-244X-7-SI-SII0

This abstract is available from: http://www.biomedcentral.com/I47I-244X/7/SI/SI I0

(C) 2007 Amering and Schaffer; licensee BioMed Central Ltd.

\section{Background}

Psychiatric Advance Directives (PAD) offer persons the opportunity to specify treatment preferences - and register opposition to certain interventions - in the event of a future loss of capacity. PADs are introduced and promoted as vehicles for enhancing the autonomy of mental health service recipients and decreasing coercive measures in psychiatric emergencies. A scientific consensus on what the intervention is and under which circumstances it unfolds which effects is yet to be reached.

\section{Methods}

An overview of the published literature on PADs will be used to illustrate and discuss their relevance, meaning, and effects on patients and on the mental health system $[1,2]$.

\section{Results}

There is little question about the high level of interest on the part of consumers, their families and providers. Nor do comprehension or ability to complete a meaningful PAD appear to be commonly encountered barriers, even for those suffering from severe mental disorders. However, progress toward implementing PADs as a routine provision in mental health has not kept pace with such enthusiasm. The complexity of the process of drafting advance directives and the lack of consensus on what kind of support should be offered necessitate ongoing conceptual and research efforts. Legal knowledge as well as ethical considerations vary among the professionals that represent the mental health system vis a vis a patient with an advance directive.

\section{Conclusion}

Obstacles to be overcome in order to use the potential of PADs concern consumers as well as the mental health system and individual professionals. The necessary capacity building processes are likely to empower both consumers and mental health workers.

\section{References}

I. Amering M, Stastny P, Hopper K: Psychiatric advance directives: qualitative study of informed deliberations by mental health service users. BrJ Psychiatry 2005, 186:247-252.

2. Swanson JW, Swartz MS, Elbogen EB, Van Dorn RA, Ferron J, Wagner $\mathrm{HR}, \mathrm{McC}$ auley BJ, Kim M: Facilitated psychiatric advance directives: a randomized trial of an intervention to foster advance treatment planning among persons with severe mental illness. Am J Psychiatry 2006, 163:1943-195I. 